\title{
Design of E-training Management System of VLE to Improve Information Literacy
}

\author{
Jinfang $\mathrm{Li}^{1, \mathrm{a}^{*}}$, Yawen $\mathrm{Li}^{2, \mathrm{~b}}$ \\ ${ }^{1}$ Lib No.105 North Xi San Huan Road,Hai Dian Dist, Bei Jing, China \\ 2 IC. No.97 East Bei Si Huan Road,Chao Yang Dist ,Bei Jing, China \\ ali_jinfang@126.com, byawen@buu.edu.cn
}

\begin{abstract}
Keywords: E-training management system; Information Literacy; VLE
Abstract. To help students gain a deep understanding of information literacy and master the skills of consistent search strategies, the E-training management system of classic VLE, with a personal response platform, is designed from the perspective of students' features and needs. Valid conclusions are drawn in successive years with the help of empirical evidence and statistical methods. It is shown that this system has been substantially increasing the efficiency of computer-assisted training activities for all students under investigation. Moreover, it helps establish a new relationship between students and librarians in that student behaves as information offers and librarians assistants in the learning and researching activities.
\end{abstract}

\section{Introduction}

VLE is an integrated university environment where students can apply for admission over the internet, enroll in the classes offered by VLE after admission, access a complete course, take tests, and interact with professors as well as classmates [1]. Designed to support and improve the individual study process, VLEs provide librarians with an opportunity to review their information literacy offerings from a learner's angle and to view the virtual classroom as an alternative and added-value gateway to library managed and supported information literacy. The widespread uptake of VLEs like WebCT, Blackboard, Top Class and Moodle are developed originally in universities and has highlighted the effectively-connecting needs of the teaching and information environments for students. It is realized by offering a repository for course documents, forums, chat boxes, and mass communication.

However, the long-term issue is how technologies place an influence on the way library students behave and expect [2]. Personal Response Systems (PRS) have already been experimentally deployed across disciplines, which allow instructors to pose questions and receive tabulated responses from students in real-time. Proponents of this technology herald it as an innovative means to encourage higher levels of participation, foster student engagement, and streamline the assessment process [3]. Students have various demands due to different characteristics such as curricula, experiences, needs and availabilities, thus it is not feasible to achieve the comprehensive statistics and analyses with large-varied student populations. To handle these constraints, innovative and technological solutions are taken into account to improve information literacy. E-training management system is just designed on the basis of personal response platform. This paper describes how this system supports librarians and students with three significant functions in expanding advocacy, questionnaire organization, data collection and analysis. It plays an active role in promoting resource utilization, stimulating the training demands and improving participation in Information Literacy.

\section{The E-training Management System}

In general, VLE systems commonly own such applications as e-mailing to the course group with broadcasting messages, individual dialogues between students and tutors, scheduling to accommodate timetabling information, structures to facilitate course and module description, facilities to permit other web resources to be linked in, assessment tools[4]. However, traditional VLE 
is an educator-centered system where educators supervise students and resources that belong to the course. Latest research presents that the fundamental principle of this new student-centered design focuses mainly on the learning contents. It implies that all learning features, including communication and peer review, depend on the content-based core object [5]. Such VLE has tools for administrators, librarians and students to perform their duties. Combined $\mathrm{C} / \mathrm{S}$ with $\mathrm{B} / \mathrm{S}$, the E-training management system is developed under CERNET and Internet environments, which takes SQL Server 2000 and DBMS in server to guarantee its security.

\section{A. Structure of the E-Training Management System}

The E-training management system consists of three parts, which are collection of information data, administration and statistical analysis (refer with: Fig. 1). Data collection gathers data mainly from personal response platform with online questionnaires. Administration module runs through the whole training process, such as student and questionnaire management. Student information including the characteristics of individuals and groups is inferred from student's ID card, which provides further personalization opportunities as it encapsulates information of professional discipline, level and grade. Statistical analysis module accumulates historical data such as participant lists and questionnaires, the report of which is automatically generated with two divided categories required by administrators. One is the student distribution; the other is accumulated-comprehensive statistics about the data of the whole semester.

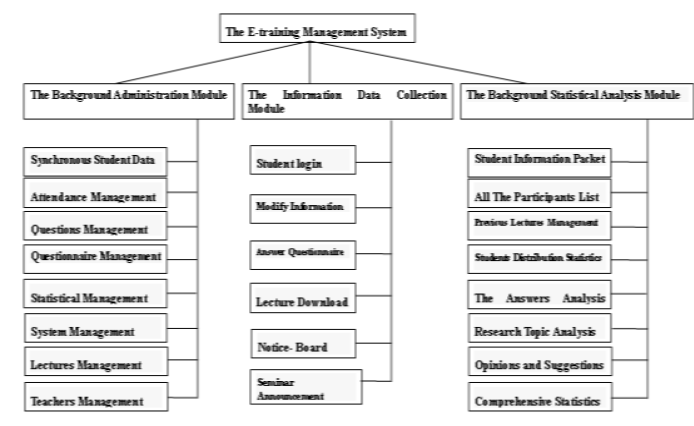

Fig. 1 Structures of the management system

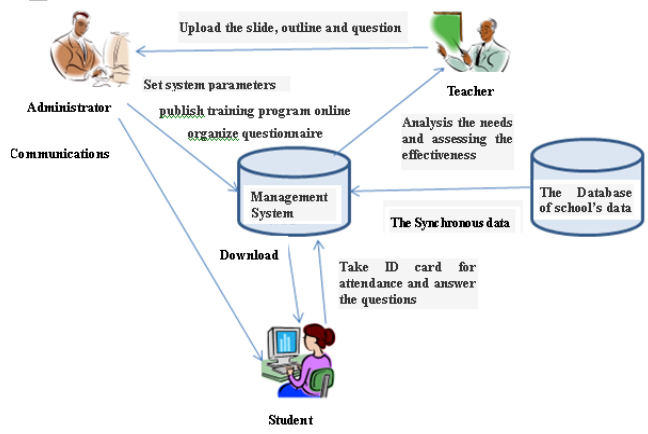

Fig. 2 The training work

\section{B. Functions of the E-Training Management System}

The routine work procedure of a complete training contains four major functions including role, student and questionnaire management as well as data statistics (refer with: Fig. 2).

Role management is designed for four types of people, administrators, teachers, tutors and students. System administrators release the training schedule in the first week of each semester. Based on the schedule, teachers and tutors can check the statistics, such as the number and distribution of the students, automatically-generated questionnaire statistics, and questions that need to be replied timely. According to the schedule time, the system can judge the student-favored training in the first place, and then prepare the corresponding notes, outlines and questionnaires.

Gained data directly from school's data center, student management takes advantage of these data to provide a convenient way to get access to a range of materials related to the training course at the beginning of a new semester. The main individual information data is registered on the student ID card. In this way, when he/she comes for training courses with an ID card and flicks it at the top of the attendance machine, the system can immediately identify and classify his/her status for further comprehensive analysis. Students can easily and quickly login into the personal response platform to communicate with teachers, and deliver their suggestions and queries. It bridges the communication between students and librarians by offering message lists.

Questionnaire management is designed according to question \& answer database, questionnaire database as well as questionnaire templates, in which questions are updated regularly. Questionnaires and data statistics are organized randomly. Administrator can renew questions and answers to organize questionnaires specific to each training. If many problems are repeated, template can be used to generate questionnaires quickly. The template mainly furnishes two types of questionnaires. One is 
universal that users can answer after they log into the system with the umber. The other is non-universal questionnaires that consist of routine questions, training contents and effect evaluation as well as views and suggestions. According to the training contents, administrators can add, modify or delete question information of template and then new network questionnaires can be designed and created. Users that answer this kind of questionnaires ought to attend the lecture and their status data have to be identified by the system. Routine questions contain utilization of user resources and demands of training topics. Training contents and effect evaluation are newly added up. One is objective questions that investigate content compositions, estimate and preset the integrating degree of training emphasis and user demands. The other is subjective questions, in which users can self-evaluate the training contents, process and methods etc. As for views and suggestions, users can offer a free evaluation and bring out individual needs. Apart from answering questions, users can as well check the registration information and have their emails reserved in advance.

In accordance with questionnaires and students' classification data, such as grade and subject, data statistics reflect the content and effect evaluation and supply reference with modification or adjustment. For example, if a large number of students are interested in the same content, the next courses should be relatively concentrate and enhance more on this part. Comprehensive statistics include participation times, trends and distributions. Attending times are expressed by calculating the ratio of all participations and the average participations, the exceeding proportion of which is to assess students' satisfaction. Statistic trend provides the utilization and requirement features of undergraduate and postgraduate students in different grades. Statistic distribution is to analyze the general and specific characters mainly according to the disciplinary characteristics such as humanities, social science, science, and engineering, which provide references for further professional and personalized training.

\section{Methods}

This study is an exploratory research using quantitative as well as qualitative methods to investigate the implementation. Methods of this research include questionnaire survey and data analysis. Such elements as training contents, place and time arrangement, training materials and survey questions are roughly identical in the first semester. The analysis ignores the subtle effects caused by these differences and the tiny difference of the registered freshmen in the following two years. Because of the large number of question types, multiple methods are used to generate and analyze different data to receive considerable attention in the field of educational research. Effect estimated from resource use, content item and other related aspects proposed by students is reported to improve students' actual observations and feedback. Purpose of this paper is to provide an overall picture of students' perceptions and usage of the designed VLE.

\section{Analyses and Results}

From the perspective of resource utilization, demands of the training content and the participation evaluation, effects of the E-training management system are evaluated based on the statistical data gained from the first semester of two school years before (Year0) and after(Year1) using this system. There are 373 students and 603 students participated and completed in the training respectively in the different first semesters.

\section{A. Promote Library Use}

In this project, it employs technologies aimed at advertising the existence of library training, promoting the library use, and provoking students to adopt a more active approach to information as a recursive process.

Results obtained suggest that students adapt easily to the use of this system and feel democratically empowered to respond to their instructors in a variety of ways. Management system provides focused and targeted survey topics and fast data report automatically for students to understand the library resource utilization and service acceptation in various types of scientific research practices. In this 
way, libraries can be promoted for targeted group. Results also show that the outstanding utilization grows in various resources in addition to the foreign language books, especially in Chinese databases (refer with: Fig. 3). With a quick access and one more person use at a time, electronic resources become the favorite approach of students to get information. At the same time, in the process of selecting and using resources, students begin to care about how to obtain resources that are not stored in their library, thus such applications of service are promoted, like interlibrary loan and document delivery. Through the survey, it gets to know students' further preferences; therefore, the library information resources are greatly advertised and the utilization of library resources and service is gradually promoted.

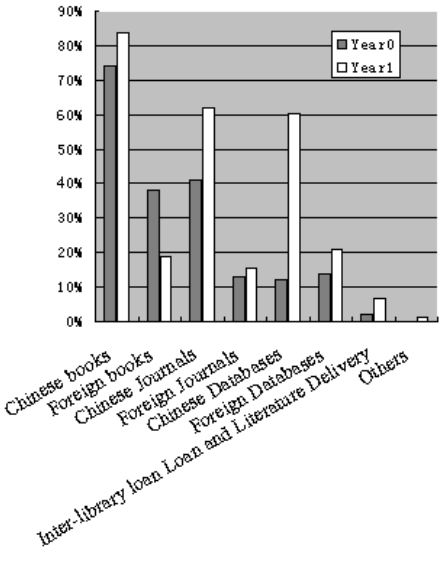

Fig. 3 Library resource use of year 0 and year 1

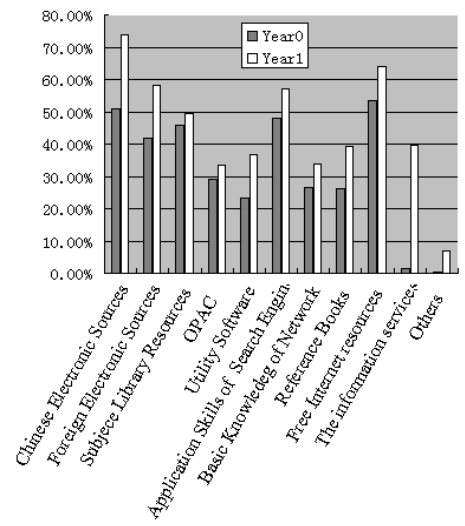

Fig. 4 Demanded training content of year 0 and year 1

\section{B. Provoke the Needs}

Data analysis is conducted with a micro-level empirical analysis on the well-managed and well-implemented training, and it is found out that the existing system provokes students' needs, which can describe their expectations (refer with: Fig. 4). First of all, library information service is being cared and stressed from almost zero to about $40 \%$. It is always a difficult problem to popularize the library, of which changing teaching methods is considered as a key measure. Combined the inquiry teaching method with traditional teaching method, it can optimize the teaching process involving research and study. In a series of trainings, students are guided to solve problems in the process of research by querying the research subjects provided by students, on the basis of which, the new information service is paid more attention to gradually and students would like to obtain help from the library in their research and study process. Second, it inspires subjective, personalized and specialized training as well as the common needs. Moreover, utility software like SPSS and ORIGIN are also put forward besides commonly-used office software. Such highly personalized need is presented; the administrator can promptly communicate with students to ensure an efficient and effective training service. At the same time, students are encouraged to think critically and actively, which can help them obtain high-quality and efficient studies, and promote a variety of training forms such as customized training or one-to-one training for teachers, special subject groups, one course.

\section{Improving involvement and Encouraging Shares Greatly}

The management system offers librarians an opportunity to establish a more engaged relationship with students. Thus it can collect opinions and suggestions and make analysis of the quick-pointed references. The effective communication and feedback through emails, MSN, QQ, etc. guarantees the immediate contact with students. The representations, acquisition of personalized requirements are of great concern. Librarians can quickly measure students' engagement, obtain new ideas and learning objectives at point-of-need, and permit students to process the information, reflect and communicate about a variety of learning problems at various levels of difficulties. The training with general recommendations takes on a rapid growth over the next year from 373 to 603(refer with: Table 1). Results indicate that students respond positively to the use of this system in and after classes, and that the combination of technology and provocation style encourages a dramatic increase up to $61.66 \%$. Besides, the average participants' participation, shown in Table 1 and an ensuing increase in student 
activities. The same theme attendance increases to a different extent. The number of consistently popular themes such as the retrieval and utilization of Chinese full text journal database increases from 54 up to 63, while the retrieval and acquisition of library collections jumps from 11 to 41 . The publicity of management system cannot be ignored.

Table 1 Stastics of Participants

\begin{tabular}{|c|c|c|c|}
\hline Content & Participants Numbers & Training Numbers & Average Participants \\
\hline Year & 373 & 10 & 37.3 \\
\hline Year0 & 603 & 11 & 54.9 \\
\hline
\end{tabular}

Table2 Statistics of Students

\begin{tabular}{|c|c|c|c|c|}
\hline $\begin{array}{c}\text { Content } \\
\text { Year }\end{array}$ & $\begin{array}{c}\text { Student } \\
\text { (A) }\end{array}$ & Average Training (N) & Students with n>N (B) & Proportion of B/A \\
\hline Year0 & 233 & 1.6 & 42 & $10 \%$ \\
\hline Year1 & 333 & 1.8 & 73 & $22 \%$ \\
\hline
\end{tabular}

Management system provides a demand response-feedback platform, carries out the two-way interactive communication between administrator-teacher and teacher-student, and encourages and promotes students to pay more and more attention to participate in a training shown in Table 2 . Students can determine the contents that best fit their own understanding and learning outcomes, and evaluate the student-centered training, which is obviously different from the traditional teaching modes. Increasing student participation is also a benefit of the system, which uses interactive technology to engage passive students into sharing knowledge and ideas, and help foster a more active approach to learn. The number of students rises up to $42.92 \%$,from 233 up to 333(refer with: Table 2), while proportion of $\mathrm{B} / \mathrm{A}$ increases from $10 \%$ to $22 \%$. With the E-training management system technology, it is able to understand students' perceptions of library and librarian as well as their varying interests, research styles and actual research practices. It attempts to promote active learning by encouraging students to think critically about the various ways that library research can offer them and help them achieve broader course objectives.

\section{Conclusions and Future work}

\section{A. Summary of Research Findings}

For this case study, the system is employed to help move away from traditional information literacy instructions. It not only transfers actual skills, but also advertises the existence of training courses.

Based on the management system, the training work is optimized, including:

- Deliver the information to one student or a group of students with some common characteristics.

- Create a virtual co-operated learning environment with student-centered learning approach and establish the demand-oriented training.

- Improve the guidance and communication, guarantee interactive communication, and strengthen the branded training construction.

- Establish standard training services, clarify the different roles of librarians and implement training service process, standardization and visualization.

- Perfect the multi-party participation with closed feedback loop mechanism, reduce students' expectation and perception of quality differences, and improve customers' satisfaction.

The primary value attributed to E-training management system is its ease of use in the activities such as share document, survey and announcement to students, which first help cross borders of time and space. The secondary use is important for communication. The system enables email lists to be generated automatically. It shares the school's enrollment information, provides students simple automatic registrations without authentication when they participate in with a campus ID card. In the university-wide LAN (local area network), students can communicate with teachers about their encountered problems and what they need. It is convenient to evaluate effects. Existing problems and feedback messages are put forward in the meantime. Teachers, students and management system become an organic entity, which promote collaborative learning and knowledge, idea and opinion sharing to encourage knowledge creation and communication. The system has solved the data acquisition bottleneck, broadened data analysis and further utilization, and laid foundation for the 
further research on the student-centered information literacy activities and the designed VLE. It is possible to investigate students' learning behavior based on objective measurements that are otherwise unavailable, which provides a scientific theory for further practices.

\section{B. Further Research}

VLEs have the potential to change the activities, including learning experience of students and the process of teaching and learning. The core features of the VLEs are to guarantee a quick, easy and convenient way for students to engage into collaboration or communication of the chosen courses. For example, several forums and instant messaging facilities are available to pose questions or to collaborate in various ways. Thus it can develop the interactive, coordinative functions and more external links including Wiki, Blog in the next step from students' perspectives and experiences. Take Wiki for example. It can help build an online item on a special subject, and students may contribute and be creative to offer information. It not only expands training content, but also supports groups with the same hobbies, characteristics and needs to take a topic into discussion, analysis and argument. Thus it enhances the brand cohesion and cultivates more loyal customers. From information managerial perspective, it would be more interesting to set an individual student as information point, similar to Facebook. Rather than emphasize libraries as smart places, Maija Berndtson would like to describe libraries as social places that change people's characters [6]. Each and every one is an information node in the system as the information knowledge in practices or actions are supposed to place an influence on another individual's innovativeness. By integrating the response platform, the online courses and the communication functions, it can build an all-around E-training management system for one-stop service. It will be more convenient for students to get access to and spread knowledge. This personalization on the basis of group and individual attributes allows libraries not only to present students with deep contextual links to key services, but also to potentially tailor the presentation of these services to meet the information competency level and role of the students on a group basis [7].

\section{References}

[1] A. Kumar, R.P. Kala, R.K. Ragade, and J.P. Wong, The virtual learning environment system, IEEE, 2 (1998)711-716.

[2] Information on http://www.ariadne.ac.uk/issue46/dempsey/(accessed 6th May 2015).

[3] M.A. Matesi, Provocation to Learn-A study in the use of personal response systems in information literacy instruction, The Canadian Journal of Library and Information Practice and Research, 1(2008)1-14.

[4] J. Maccoll, Virtuous learning environments: the library and the VLE, Program, 3(2001)227-239.

[5] P. Wessa, A. De Rycker, IE. Holliday, Content-Based VLE Designs Improve Learning Efficiency in Constructivist Statistics Education, PLoS ONE, 10(2011) 1-15.

[6] M. Berndtson, "What and why libraries?": looking at what libraries might look like and why we still need them now and into the future, Library Hi Tech News, 4(2012)13-15.

[7] A. Masson,VRE library services: Learning from supporting VLE studentss, Library Hi Tech, 2 (2009)217-227. 